\title{
The Correlation Study of Interest at Physics and Knowledge of Mathematics Basic Concepts towards the Ability to Solve Physics Problems of 7th Grade Students at Junior High School in Ambon Maluku Province, Indonesia
}

\author{
Izaak Hendrik Wenno \\ Physic Education Programme, Department of Science Education, Faculty of Teaching and Education, Pattimura University, \\ Ambon, Maluku 97116, Indonesia \\ Correspondence should be addressed to Izaak Hendrik Wenno; wennoiz@yahoo.co.id
}

Received 29 May 2014; Revised 20 November 2014; Accepted 20 December 2014

Academic Editor: Eduardo Montero

Copyright (C) 2015 Izaak Hendrik Wenno. This is an open access article distributed under the Creative Commons Attribution License, which permits unrestricted use, distribution, and reproduction in any medium, provided the original work is properly cited.

\begin{abstract}
The purpose of the study is to determine the relation between interest at Physics and knowledge of Mathematics basic concepts with the ability to solve Physics problems. The populations are all students in the 7th grade at the junior high school in Ambon, Maluku, Indonesia. The used sample schools are Junior High Schools 8, 9, and 10 during 2013/2014 academic year with 44 students per school. Two independent variables and one dependent variable are studied. The independent variables are the interest at Physics $\left(X_{1}\right)$ and the knowledge of Mathematics basic concepts $\left(X_{2}\right)$, while the dependent variable is the ability to solve Physics problems $(Y)$. Data collection technique for $X_{1}$ is an interview with questionnaire instrument, while for the $X_{2}$ and $Y$ is using the test technique with test items instrument. The obtained data from the measurements were analyzed with descriptive analysis and inferential analysis. The results show that there is a positive relation between interest at Physics and knowledge of Mathematics basic concepts with students' ability to solve Physics problems.
\end{abstract}

\section{Introduction}

In this more advanced transformation, information, and technology era, one of the lessons considered important as the basic for knowledge and technology acquisition is Physics $[1,2]$.

This quite makes sense, because Physics is part of science [3-5], where science has direct effects and relation to various life fields and also jobs based on information and technology $[3,6,7]$. Further, [7] states that almost every life fields have relation with Physics like organisms or inanimate, from Engineering to Mathematics, Biology, and Chemistry. According to [5], without Physics science knowledge, human will face difficulties in exploring the universe. Furthermore, $[4,8]$ stated that the understanding of Physics helps to understand the content of universe and, for students, it helps to develop the observation skill, accuracy, analysis ability, creative thinking, and Physics science acquisition which is now is very required and cannot be avoided by students [6].
Nevertheless, the student result study of Physics is still low in all levels [6] in junior high school level [9], or in senior high school level [10] as well as in higher education level [5]. The low student study result of Physics is caused by many factors such as intern and extern factors from the students $[11,12]$. The intern factors may be the attitude, motivation, interest, knowledge, skills, hope, assumption, and goals [1115], while the extern factor is the student study environment condition [11, 12], like the utilization of teaching method by the teachers [2], family environment, and the availability of learning facility and infrastructure [13, 15-17].

One of the intern factors affecting the study achievement is student interest to the material taught. As mentioned in [18] if a student has high study interest, the study result tends to be high. In contrast, if the interest is less, the study result will be low.

The low of student result study in Physics so far, is also caused by Physics is considered as a difficult lesson for the students, especially if the materials are related to 
Mathematics calculation $[3,14]$. On the other side, the Physics comprehension needs knowledge of Mathematics concepts. According to [19] there is a positive correlation between Mathematics acquisition and the success in Physics study result achievement. The relation between Mathematics acquisition and Physics study result is reported by many researchers. As reported in [10] one cause of student difficulty in studying Physics is the mathematic ability weakness. Also, [20] reports that there is a linear relation between the comprehension of Mathematics concept and the ability to solve Physics problems, while [21] states that student having high Mathematics ability has effects to student achievement of Physics study.

Learning Physics is also related with the ability to solve problems. According to [22] problem solving has important role in Physics learning. Further, it is stated that problem solving aims at developing the transformation skills including problem observation, proposing questions, formulating hypothesis, planning examination, conducting examination, analysis and data interpretation, and communicating the results.

The Physics study result of Junior High School students in Ambon, Maluku province, so far has not showed maximum result. On the other side, there is no research to know student interest at Physics and/or knowledge of student basic concept of Mathematics and its correlation to the Physics study result of Junior High School students in Ambon. This is because so far, the research is conducted separately by Mathematics and Physics researchers without considering the importance of these two combinations; instead according to [19], students' Physics ability is affected by student experience in studying Mathematics. This shows that comprehension of Physics requires Mathematics acquisition. Besides, although it is known and as an open secret that interest, as well as the knowledge of Mathematics basic concept must be related to students' ability to solve problems or students' result study not only in Physics, but also other fields, but this kind of research has not been ever conducted to Junior High Schools 8,9 , and 10 . However, to increase student study result of Physics, it is very necessary to require some factors affecting student study result like the interest at Physics and knowledge of Mathematics basic concept as the initial information for teacher to develop successful learning.

Based on this background, this research aims to know (1) the relation between interest at Physics and ability to solve Physics problems, (2) the relation between knowledge of Mathematics basic concept and ability to solve Physics problems, and (3) the collective relation between interest at Physics and knowledge of Mathematics basic concept and the ability to solve Physics problems for Junior High School students in Ambon.

\section{Method}

This research uses survey method with ex-post-facto technique. The ex-post-facto research is conducted by taking samples from a population and using questionnaire as a tool for collecting data, so in this research, the researcher does not conduct any treatment or control to the research subjects but

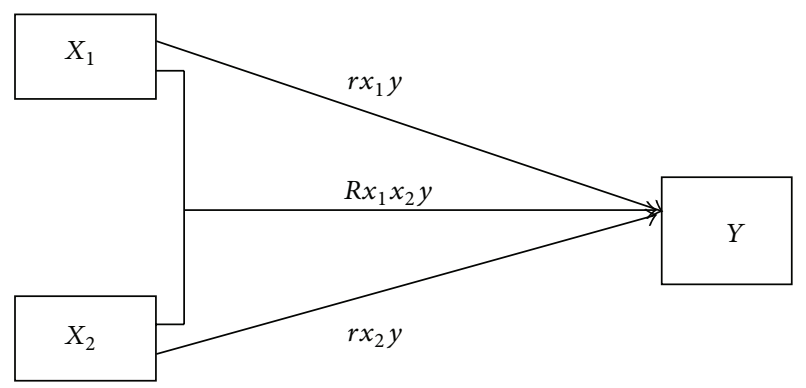

Figure 1: The Research Problem Constellation. Note: $X_{1}$ : the interest at Physics (IP), $X_{2}$ : the knowledge of Mathematics basic concept (KMBC), $Y$ : the ability to solve Physics problems (ASPP), $r x_{1} y$ : the relation between interest $\left(X_{1}\right)$ and $\operatorname{ASPP}(Y), r x_{2} y$ : the relation between IP $\left(X_{2}\right)$ and ASPP $(Y)$, and $R x_{1} x_{2} y$ : the relation between interest $\left(X_{1}\right)$ and $\operatorname{KMBC}\left(X_{2}\right)$ to $\operatorname{ASPP}(Y)$.

only reveals facts through existence symptom measurement to the respondents. The research variables are interest at Physics $\left(X_{1}\right)$ and knowledge of Mathematics basic concept $\left(X_{2}\right)$ as independent variables, while the dependent variable is the ability to solve Physics problems ( $Y$ ) (Figure 1).

The school selection is conducted by purposive sample technique, namely, State Junior High Schools 8, 9, and 10. The research is conducted for 3 months in odd semester of 2013/2014 academic year. The research population is all students in 7th grade from those all schools. Because each school has different number of student, to uniform the sample number, it takes 44 students randomly, so the total sample number is 132 students consisting of 80 male students and 52 female students with the average age being $12-13$ years. The selection of students as sample was used by random sampling technique.

The research instruments are two kinds that are questionnaire and test item. The questionnaire to measure independent variable of interest at Physics is 40 questions (obtained after validity test of 57 questions before validity test) referring to Likert scale with answer options being very agree, agree, doubt, disagree, and very disagree. The instrument of test problem question is to measure the independent variable of Mathematics basic concept knowledge $\left(X_{2}\right)$ is 30 questions (obtained after validity test of 43 items before validity test) with multiple choice questions referring to the concept: row, algebra operation, trigonometry, equation, and inequality. For dependent variable of problem solving in Physics, the 11 subjective test questions are used (obtained after validity test of 13 questions before validity test) and arranged based on the main material of time, distance, and speed. The questionnaire and test problem are developed by the researcher himself; both the validity and reliability also are tested.

The instrument validity test is conducted with the correlation formula of product-moment from Pearson. The criteria are valid with the value of $r_{\text {calculation }}>r_{\text {table }}$ at the significance level of $\alpha 0.05$. The instrument reliability test is conducted by following Alpha Cronbach coefficient formula. As mentioned in [23] if the Alpha Cronbach value is $>0.60$, the questions to measure the observed variables have high reliability. 
TABLE 1: The instrument validity and reliability analysis results.

\begin{tabular}{|c|c|c|c|c|c|}
\hline \multirow{2}{*}{ Instrument } & \multicolumn{2}{|c|}{ Validity } & \multirow{2}{*}{ Note } & \multirow{2}{*}{ Reliability } & \multirow{2}{*}{ Note } \\
\hline & $r_{\text {calculation }}$ & $r_{\text {table }}$ & & & \\
\hline Interest at Physics & 0.80 & \multirow{3}{*}{0.195} & \multirow{3}{*}{ Valid } & 0.90 & \multirow{3}{*}{ Reliable } \\
\hline Knowledge of Mathematics basic concept & 0.75 & & & 0.71 & \\
\hline Ability to solve Physics problems & 0.50 & & & 0.72 & \\
\hline
\end{tabular}

TABLE 2: The normality and homogeneity test results $(n=132)$.

\begin{tabular}{lccccccc}
\hline & \multicolumn{2}{c}{ Normality test } & & & \multicolumn{3}{c}{ Homogeneity test } \\
Error estimation & $L_{\text {calculation }}$ & $L_{\text {table }}$ & Note & Error estimation & $\chi_{\text {calculation }}^{2}$ & $\chi_{\text {table }}^{2}$ & Note \\
\hline$X_{1}$ to $Y$ & 0.0689 & 0.0771 & Normal & $X_{1}$ to $Y$ & 26.83 & 67.50 & Homogen. \\
$X_{2}$ to $Y$ & 0.0652 & 0.0771 & Normal & $X_{2}$ to $Y$ & 25.14 & 32.70 & Homogen. \\
\hline
\end{tabular}

The procedure consisted of three stages. The first stage carried out preparation of research instrument which includes a questionnaire to measure the variables of interest at Physics and test items to measure the variable knowledge of Mathematics basic concepts and ability to solve Physics problems. The second stage is the analysis instrument that includes test validity and reliability. The third stage is the provision and implementation of test questionnaire to students.

From the result data of interest at Physics and knowledge of Mathematics basic concept, its normality and homogeneity are tested. The normality test uses Liliefors test to tyest two hypotheses, namely, $H_{0}$ : samples are from abnormal distribution population, and $H_{1}$ : samples are from normal distribution population. The criterion is normality if the samples are from normal distribution population.

The homogeneity test is conducted by following Bartlet method with chi square analysis technique testing two hypotheses, namely, $H_{0}$ : samples are from inhomogeneous population, and $H_{1}$ : samples are from homogeneous population. If the sample from normal distribution population is $\left(L_{\text {calculation }}<L_{\text {table }}\right)$ and homogeneous $\left(\chi_{\text {calculation }}^{2}<\chi_{\text {table }}^{2}\right)$, it can be continued with hypothesis analysis.

To know the relation between independent and dependent variables $\left(X_{1}-Y\right),\left(X_{2}-Y\right)$, and $\left(X_{1}, X_{2}-Y\right)$, the multiple correlation analysis is conducted using product-moment correlation. The results of multiple correlation analysis between independent and dependent variables are also tested its linearity to know whether the correlation is linear or not. This is by testing the research hypothesis significance by value measurement of regression coefficient to obtain regression equation. Then, the significance test of regression equation is conducted using variance analysis. The significance criteria of regression equation are if $F_{h}>F_{\text {table }}$ of $\alpha 0.05$ the regression equation is significant, whereas if $F_{\text {calculation }}<$

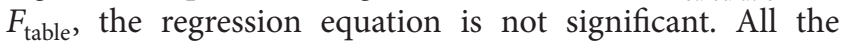
statistical analysis was done by using the Statistical Package for Social Sciences (SPSS) version 18.0 for Windows.

\section{Results and Discussion}

3.1. The Instrument Validity and Reliability Analysis Results of Independent and Dependent Variables. The instrument validity and reliability analysis results (Table 1) show that the used problem questions in this research are valid and reliable, both for the questionnaire for interest at Physics variable or test instrument for knowledge of Mathematics basic concept and ability to solve Physics problems variables.

3.2. The Normality and Homogeneity Analysis Results. Based on the normality and homogeneity calculation conducting to all 132 respondent data including the variables of interest at Physics, knowledge of Mathematics basic concept, and ability to solve Physics problems (Table 2), evidently, the samples are from normal and homogeneous distribution, so the multiple correlation analysis can be conducted to know the relation between independent and dependent variables.

3.3. The Multiple Correlation Analysis Results of Independent and Dependent Variables $\left(X_{1}-Y ; X_{2}-Y\right.$; and $\left.X_{1}, X_{2}-Y\right)$. The multiple correlation analysis to the independent variable data of interest at Physics $\left(X_{1}\right)$, the knowledge of Mathematics basic concept $\left(X_{2}\right)$ also interest at Physics, and knowledge of Mathematics basic concept collectively with the ability to solve Physics problems ( $Y$ ) are shown in Table 3.

The multiple correlation analyses of $X_{1}$ variable to $Y, X_{2}$ to $Y$, and $X_{1}, X_{2}$ to $Y$ are conducted to test the zero hypothesis $\left(H_{0}\right)$ stating that there is no relation between interest at Physics, knowledge of Mathematics basic concept, and both collectively with the ability to solve Physics problems; and also alternative hypothesis $\left(H_{1}\right)$ is stating that there is relation between interest at Physics, knowledge of Mathematics basic concept, and also both collectively to problem solving ability in Physics, with the hypothesis acceptance criteria being if the $r$ calculation is bigger than $r$ table, the $H_{0}$ is accepted, and $H_{1}$ is rejected, whereas if the $r$ calculation is bigger than $r$ table $\left(r_{h}\right.$ $>r_{t}$ ) $H_{1}$ is accepted and $H_{0}$ is rejected.

In Table 3, it is shown that the variables of interest at Physics $\left(X_{1}\right)$, knowledge of Mathematics basic concept $\left(X_{2}\right)$, and also interest at Physics and knowledge of Mathematics basic concept collectively $\left(X_{1}, X_{2}\right)$ show significant relation with the ability to solve Physics problems with the values of $r_{\text {calculation }}$ and $r_{\text {table }}$, respectively, are: $\left(r_{\text {calculation }} 3.60>\right.$ $r_{\text {table }} 1.65$ to $\left.\alpha 0.05\right),\left(r_{\text {calculation }} 4.54>r_{\text {table }} 1.65\right.$ to $\left.\alpha 0.05\right)$, and $\left(r_{\text {calculation }} 11.36>r_{\text {table }} 3.06\right.$ to $\left.\alpha 0.05\right)$. These results 
TABLE 3: The correlation analysis of independent and dependent variables.

\begin{tabular}{lcccccc}
\hline Variable & Correlation coefficient $(r)$ & Determination coefficient $\left(r^{2}\right)$ & $R_{\text {calculation }}$ & $r_{\text {table }(0.05)}$ & Significance & $H_{0}$ \\
\hline$X_{1}-Y$ & 0.30 & 0.09 & 3.60 & 1.65 & Significant & Rejected \\
$X_{2}-Y$ & 0.37 & 0.14 & 4.54 & 1.65 & Significant & Rejected \\
$X_{1}, X_{2}-Y$ & 0.39 & 0.15 & 11.36 & 3.06 & Significant & Rejected \\
\hline
\end{tabular}

TABLE 4: The significant test result of research hypothesis.

\begin{tabular}{lcccc}
\hline Variable & Regression equation & Constant $(a)$ & Regression coefficient $(b)$ & $H_{0}$ \\
\hline$X_{1}-Y$ & $\widehat{Y}=8.68+0.12 X_{1}$ & 8.68 & 0.12 & Rejected \\
$X_{2}-Y$ & $\widehat{Y}=18.81+0.20 X_{2}$ & 18.81 & 0.20 & Rejected \\
$X_{1}, X_{2}-Y$ & $\widehat{Y}=10.98+0.05 X_{1}+0.31 X_{2}$ & 10.98 & $0.05\left(X_{1}\right)$ & Rejected \\
\hline
\end{tabular}

cause the rejected of null hypothesis stating that there is no relation between interest at Physics and knowledge of Mathematics basic concept and also the combination of the two to the ability to solve Physics problems and knowledge of Mathematics basic concept, or the combination of the two to the ability to solve Physics problems.

3.4. The Significant Test of Research Hypothesis. The significant test of research hypothesis is conducted to the results of multiple correlation analysis to know whether the correlation between $X_{1}-Y, X_{2}-Y$ and $X_{1}, X_{2}-Y$ variables collectively is positive and strong relation (Table 4 ).

From Table 4, it can be seen that the zero hypothesis to know the three variables is rejected, meaning that the relation between independent variables of $X_{1}-Y, X_{2}-Y$ and also $X_{1}, X_{2}-Y$ collectively is linear and strong relation. Further, to know whether the regression coefficient between the three variables is significant, regression significant test is conducted through $F$ test (variance analysis) (Table 5).

The analysis result of regression significance using variance analysis ( $F$ test) shows that the variables of interest at Physics, knowledge of Mathematics basic concept, and both collectively to the ability to solve Physics problems give bigger value of $F_{\text {calculation }}$ than $F_{\text {table }}$ at significant level of $\alpha 0.05$, respectively, are: $\left(F_{\text {calculation }}=12.37>F_{\text {table }}=\right.$ $3,91),\left(F_{\text {calculation }}=10.90>F_{\text {table }}=3,91\right)$, and $\left(F_{\text {calculation }}=\right.$ $\left.11,10>F_{\text {table }}=3,06\right)$. These results cause $H_{0}$ to be rejected meaning that the regression coefficient of student interest at Physics, knowledge of Mathematics basic concept $\left(X_{2}\right)$, and both $\left(X_{1}, X_{2}\right)$ collectively to ability to solve Physics problems is significant and linear.

\section{Discussion}

The significant relation between interest at Physics and ability to solve Physics problems shows that higher student interest at Physics makes higher ability to solve Physics problems. This may happen, because as said in [24] the interest is a constant tendency to conduct an activity. The interest is also defined as a feeling of like, eager, giving attention, without any forces, and interest at something. Someone having high interest tends to give big attention to that something. As well as in studying Physics, if the students have interest at the taught material, they will be motivated to give all attention to taught materials, and finally, it will give positive effects to the study results.

The significant relation is also showed by the variable of knowledge of Mathematics basic concept to the ability to solve Physics problems. As stated by [25] there is a strong relation between Physics and Mathematics, while [26] states that Physics and Mathematics have similarity that is knowledge aiming at forming student skills in decision making and problem solving. It is clear that knowledge of Mathematics basic concept is an absolute thing which has to be possessed by student in studying Physics, or, in other words, studying Physics without comprehending Mathematics is an impossible thing. This is because Mathematics reviewing simple number count concept to complex formulation, including figure, graphics, formula, equation, geometry, and many more. In learning Physics, almost all Physics concepts are related with Mathematics. Each Physics problem requires completion with mathematical approach. So, it can be said that knowing and mastering knowledge of Mathematics basic concept will be very beneficial for student in completing Physics problems.

According to [26] Mathematics provides symbols expressed in Physics to show relation structure between different factors. The same thing is also stated by [25] that the expressed symbols may enable students for deep comprehension and correcting student procedural knowledge to different but interrelated symbols required in problem solving in Physics process.

Collectively, the interest at Physics and knowledge of Mathematics basic concept both have positive and significant relation with ability to solve Physics problems. These two variables are intersupporting in increasing student ability in problem solving of Physics. If the student interest at Physics gives attention, support, and willingness for student to study Physics, the knowledge of Mathematics basic concept will spur the student to complete various Physics problems systematically. So, the research results give information that the interest at Physics as well as the knowledge of Mathematics basic concept gives positive effect to ability to solve Physics problems. 
TABLE 5: The summary of variance analysis results.

\begin{tabular}{|c|c|c|c|c|c|c|}
\hline Variable & Model & Degree of freedom & Sum of square & Middle square & $F_{\text {calculation }}$ & $F_{\text {table }} 0.05$ \\
\hline \multirow{6}{*}{$X_{1}-Y$} & $a$ regression & 1 & 66017.45 & 66017.45 & & \\
\hline & $b$ regression & 1 & 322.69 & 322.69 & 12.37 & 3.91 \\
\hline & Residual & 130 & 3390.86 & 26.08 & \multirow{4}{*}{1.62} & \multirow{4}{*}{1.78} \\
\hline & Linearity & 50 & 1705.71 & 34.11 & & \\
\hline & Error & 80 & 1685.15 & 21.06 & & \\
\hline & Total & 132 & 69731 & - & & \\
\hline \multirow{6}{*}{$X_{2}-Y$} & $a$ regression & 1 & 66017.45 & 66017.45 & \multirow{3}{*}{10.90} & \multirow{3}{*}{3.91} \\
\hline & $b$ regression & 1 & 287.26 & 287.26 & & \\
\hline & Residual & 130 & 3426.29 & 26.36 & & \\
\hline & Linearity & 50 & 907.85 & 45.38 & \multirow{3}{*}{1.98} & \multirow{3}{*}{2.12} \\
\hline & Error & 80 & 2518.44 & 22.89 & & \\
\hline & Total & 132 & 69731 & - & & \\
\hline \multirow{3}{*}{$X_{1}, X_{2}-Y$} & Regression & 2 & 579.81 & 289.91 & \multirow{3}{*}{11.10} & \multirow{3}{*}{3.06} \\
\hline & Residual & 130 & 3369.96 & 26.12 & & \\
\hline & Total & 132 & 3949.77 & - & & \\
\hline
\end{tabular}

\section{Conclusion}

Based on the data and discussion analysis results, it can be concluded that

(1) there is a positive and significant relation between interest at Physics and student's ability to solve Physics problems;

(2) there is a positive and significant relation between knowledge of Mathematics basic concept and student's ability to solve Physics problems;

(3) there is a positive and significant relation between both of interest and knowledge of Mathematics basic concept with student's ability to solve Physics problems.

\section{Conflict of Interests}

The author declares that there is no conflict of interests regarding the publication of this paper.

\section{References}

[1] D. Checkley, High School Students' Perceptions of Physics, Faculty of Education, Lethbridge, Canada, 2010.

[2] J. M. Changeiywo, P. W. Wambugu, and S. W. Wachanga, "Investigations of students' motivation towards learning secondary school physics through mastery learning approach," International Journal of Science and Mathematics Education, vol. 9, no. 6, pp. 1333-1350, 2011.

[3] F. Ben, Students Uptake of Physics: A Study of Australian and Filipino Physics Students, School of Education, Faculty of the Proffesions, University of Adelaide, 2010.

[4] A. A. Elwan, M. Serage, and A. Alwan, "The institutional factors affecting the achievement in physics in Tripoli, Libya," VFAST Transactions on Research in Education, vol. 1, no. 2, pp. 1-18, 2013.
[5] S. Mekonnen, "Problems challenging the academic performance of physics students in higher governmental institutions in the case of Arbaminch, Wolayita Sodo, Hawassa and Dilla Universities," Natural Science, vol. 6, pp. 362-375, 2014.

[6] E. E. Ukoh, "Effect of interactive invention instructional strategy on NCE pre-service teacher's achievement in physics and acquisition of science process skills," Journal of Innovative Research in Management and Humanities, vol. 3, no. 1, pp. 122131, 2012.

[7] A. Awodun, O. J. O. Omotade, and O. Adeniyi, "Mathemtics skills as predictors of physics student's performance in senior secondary schools," International Journal of Science and Research, vol. 2, no. 7, pp. 391-394, 2013.

[8] U. Siddiqui and T. Khatoon, "Teaching physical science: should we implement teacher-centered CAI or student-centered CAI at secondary school level in India?" European Scientific Journal, vol. 9, no. 10, pp. 136-149, 2013.

[9] S. Ganina and H. Voolaid, The Influence of Problem Solving on Studying Effectiveness in Physics, Natural and Exact Sciences, Estonian National Defence College and Physics Didactics of School Physics Centre, Tartu University, 2009.

[10] I. Ghozali, SPSS Application of Multivariate Analysis, Diponegoro University, Semarang, Indonesia, 2nd edition, 2001.

[11] A. Carbone, J. Hurst, I. Mitchell, and D. Gunstone, "An exploration of internal factors influencing student learning of programming," in Proceedings of the 11th Australasian Computing Education Conference (ACE '09), vol. 95 of Conferences in Research and Practice in Information Technology, pp. 2534, Australian Computer Society, Wellington, New Zealand, January 2009.

[12] E. F. Redish, "Problem solving and the use of math in physics courses," in Proceedings of the ICPE Conference, World View on Physics Education: Focusing on Change, Delhi, India, August 2005.

[13] R. M. Felder and R. Brent, "Understanding student differences," Journal of Engineering Education, vol. 94, no. 1, pp. 57-72, 2005.

[14] O. O. Olusola and C. O. Rotimi, "Attitudes of students towards the study of physics in College of Education Ikere Ekiti, Ekiti State, Nigeria," American International Journal of Contemporary Research, vol. 2, no. 12, pp. 86-89, 2012. 
[15] S. Wulan Sari, "Effect of learning model and personality type towards learning achievement of student in private junior high school in the Medan Area Sub-District," Tabularasa Journal, Post Graduate Programe of Medan State University, vol. 9, no. 1, pp. 33-44, 2012.

[16] R. Trumper, "Factors affecting junior high school students' interest in physics," Journal of Science Education and Technology, vol. 15, no. 1, pp. 47-58, 2006.

[17] M. Y. Iliya and A. Simdet, "Analysis of teachers perception of their public image and it influence on students performance in physics: a key to improving the quality of education in Nigeria," Mediterranean Journal of Social Sciences, vol. 4, no. 12, pp. 113117, 2013.

[18] S. B. Djamarah, Teaching Learning Strategy, Rineka Cipta, Jakarta, Indonesia, 2002.

[19] D. E. Meltzer, “The relationship between mathematics preparation and conceptual learning gains in physics: a possible 'hidden variable' in diagnostic pretest scores," The American Journal of Physics, vol. 70, no. 12, pp. 1259-1268, 2002.

[20] Wanhar, "The relation between mathematics mastery concepts with the ability to solve physics test," Baruga, vol. 1, no. 3, pp. 30-35, 2008.

[21] A. A. Prasetyo, Physics Teaching with Guidance Inquiry by Using Experiment and Demonstration Method in Virtual Laboratory Based on Pre-Performance and Mathematic Ability of Student (Case Study on Dinamyc Static Electricity of X Grade Student in 1 State Tanjung Selor Senior High School During 2010/1011 Academic Year), Sebelas Maret University, Surakarta, Indonesia, 2011.

[22] U. S. Supardi, Leonard, H. Suhendri, and Rismudiryati, "Effect of learning media and study interest on learning achievement in physics," Formatif Journal, vol. 2, no. 1, pp. 71-81, 2012.

[23] A. Rusilowati, "Profile of learning difficult in electric concept of student in Semarang city," Journal of Indonesian Physics Education, vol. 4, no. 2, pp. 100-106, 2006.

[24] Slameto, Learning and Affecting Factors, Rineka Cipta, Jakarta, Indonesia, 2010.

[25] P. H. Liu and S. Y. Liu, "A cross-subject investigation of college students'epistemological beliefs of physics and mathematics," Asia-Pacific Education Researcher, vol. 20, no. 2, pp. 336-351, 2011.

[26] C. Y. Long and Y. K. Jiar, "Mathematical thinking and physics achievement of secondary school students," Sains Humanika, vol. 2, no. 4, pp. 231-237, 2014. 

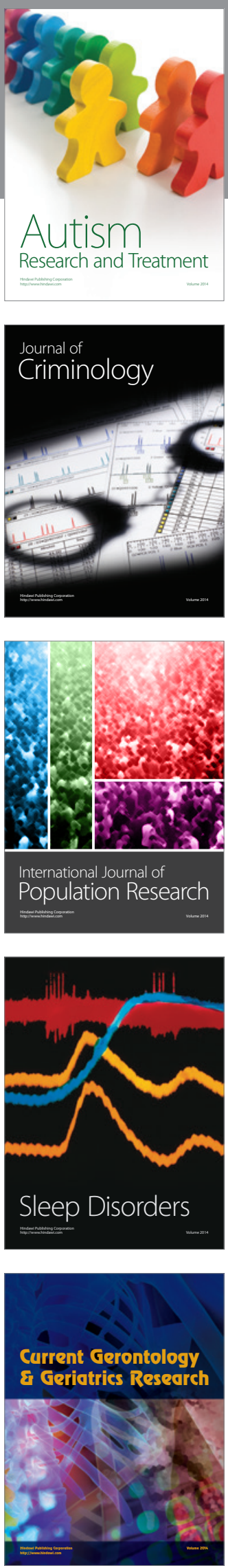
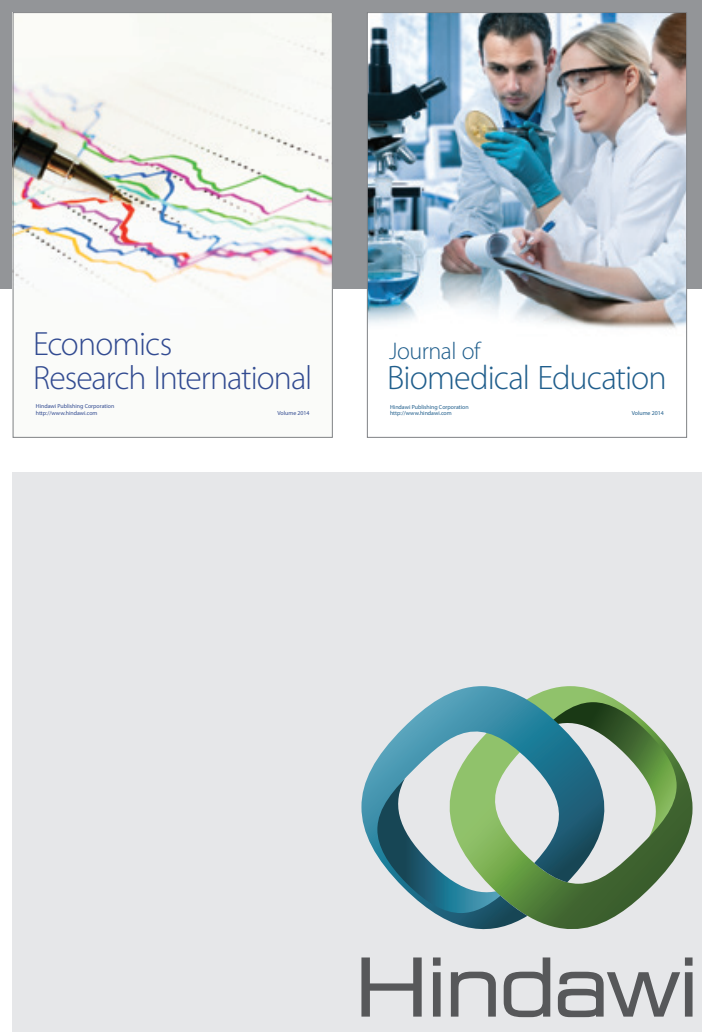

Submit your manuscripts at

http://www.hindawi.com
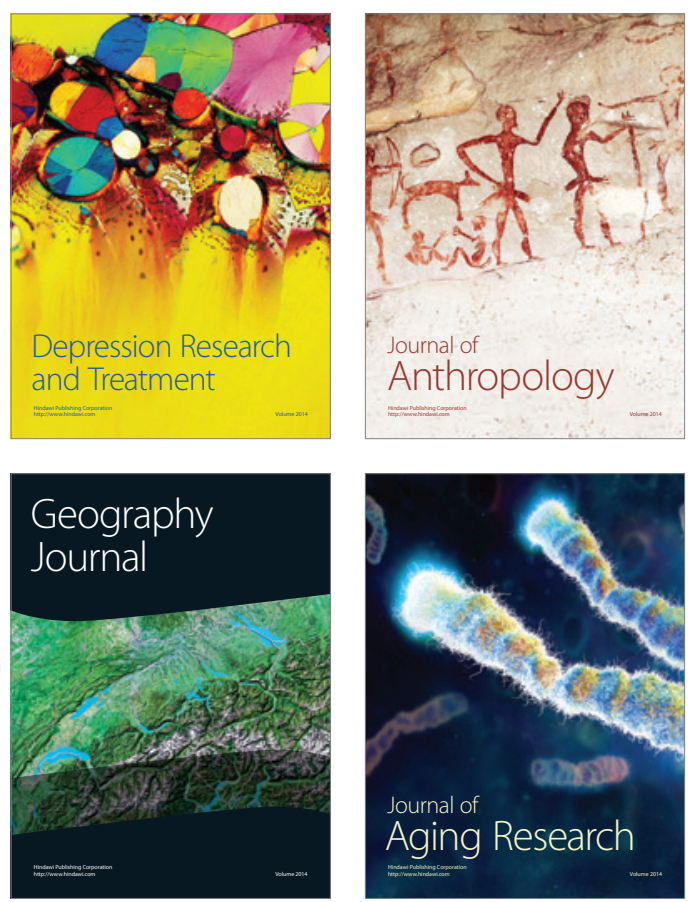
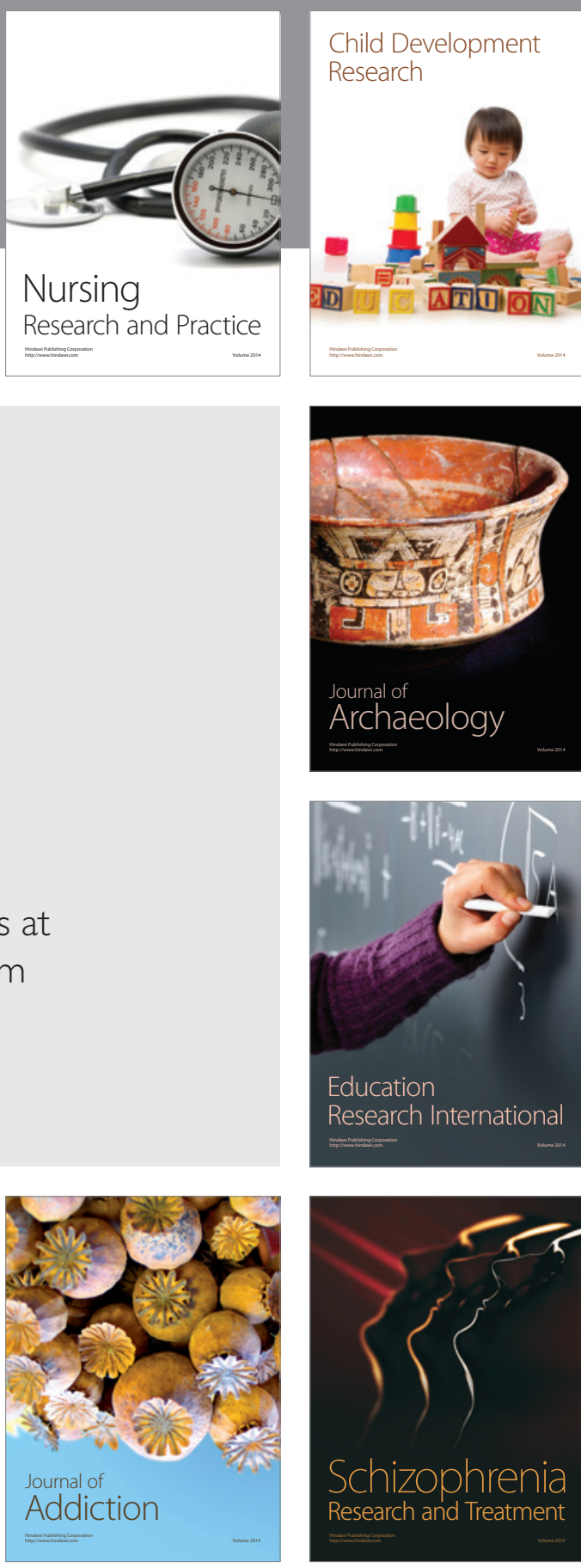

(D)
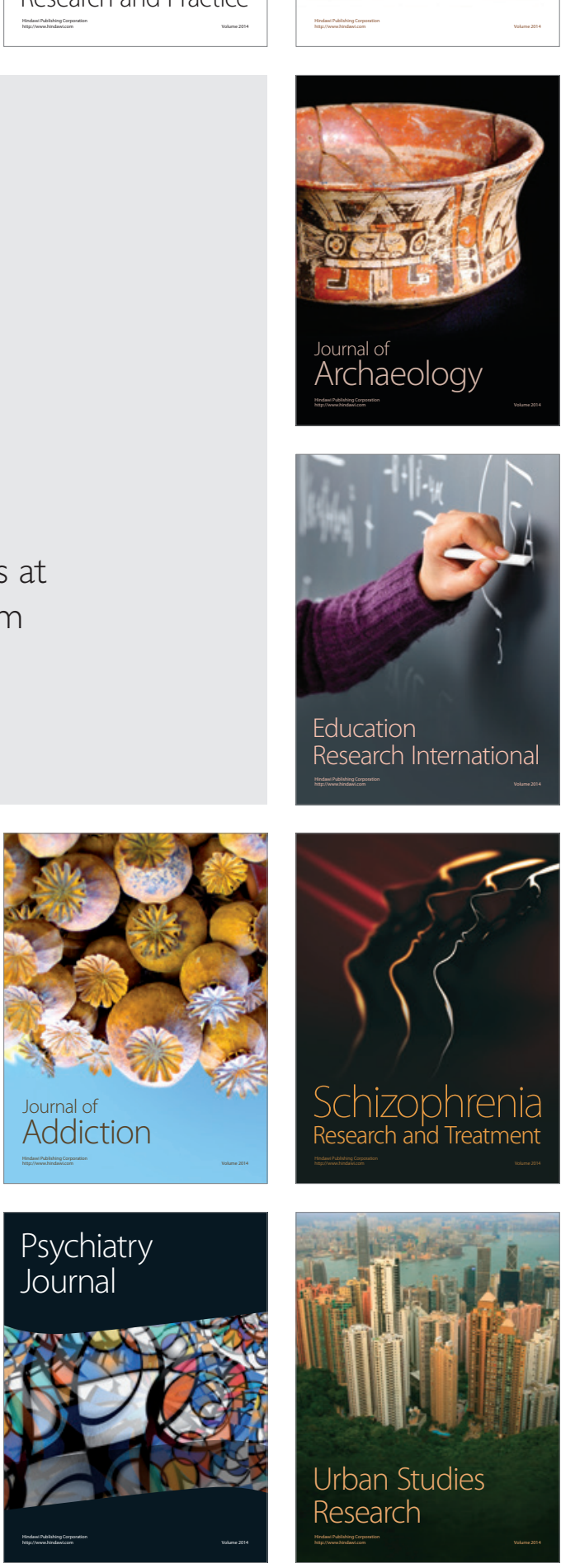